\title{
Improving guidelines for the management of coronary heart disease risk factors
}

\author{
C. Tissa Kappagoda, Ezra A. Amsterdam
}

Division of Cardiovascular Medicine, Department of Internal Medicine, University of California, Davis, California, USA

*Published in cooperation with the American Society for Preventive Cardiology (ASPC)

Submitted: 14 December 2011

Accepted: 18 December 2011

Arch Med Sci 2011; 7, 6: 923-924

DOI: 10.5114/AOMS.2011.26599

Copyright (๑) 2011 Termedia \& Banach

Corresponding author: Prof. Ezra A. Amsterdam UC Davis Medical Center Ambulatory Care Center 4860 Y Street, Sacramento CA 95817, USA

E-mail:

eaamsterdam@ucdavis.edu

"Best laid plans of mice and men..." Robert Burns

The accompanying paper by Athyros et al. [1], while drawing attention to the prognostic importance of renal function in patients with multiple cardiovascular risk factors, has focused on the larger issue of the practical difficulties involved in providing this type of care for large numbers of patients. Their study is a post hoc analysis of 5 observational studies undertaken in Greece between 2005 and 2010. These studies were designed to optimize the management of risk factors in patients with various combinations of hyperlipidemia, the metabolic syndrome (as defined by the American Heart Association and the National Heart, Lung, and Blood Institute), diabetes mellitus and overt cardiovascular disease. Their intention was to determine whether a multi-factorial/disciplinary approach would improve renal function over a 6 month period. The intervention covered hypertension, dyslipidemia, weight management, smoking cessation, titration of medications to achieve treatment targets and general lifestyle changes to promote health.

The primary end-point of the studies was effect of the multi-factorial intervention on estimated glomerular filtration rate (GFR). The secondary end-point was the effect of the intervention on serum uric acid. The distribution of chronic kidney disease (CKD) in the study population $(n=4.153)$ was as follows.

\begin{tabular}{|lcc|}
\hline CKD stage & Number of subjects $^{*}$ & Estimated GFR \\
\hline 1 & $912(22 \%)$ & $\begin{array}{c}>90 \mathrm{ml} / \mathrm{min} / 1.73 \mathrm{~m}^{2} \\
+ \text { renal damage }\end{array}$ \\
\hline 2 & $1424(34 \%)$ & $60-89 \mathrm{ml} / \mathrm{min} / 1.73 \mathrm{~m}^{2}$ \\
\hline 3 & $1235(29.7 \%)$ & $30-59 \mathrm{ml} / \mathrm{min} / 1.73 \mathrm{~m}^{2}$ \\
\hline 4 & 0 & $15-29 \mathrm{ml} / \mathrm{min} / 1.73 \mathrm{~m}^{2}$ \\
\hline 5 & 0 & $<15 \mathrm{ml} / \mathrm{min} / 1.73 \mathrm{~m}^{2}$ \\
\hline
\end{tabular}

*Number of patients in the table is less than the total number in the study because not all patients had CKD 
After 6 months of treatment, there was a 5.6\% improvement in GFR and a reduction of $6.1 \%$ in serum uric acid in stage 3 subjects. Approximately $10 \%$ of this category improved to stage 2 while $0.7 \%$ advanced to stage 4 . In stage 1 and 2 subjects there was evidence of improvement in the serum uric acid and body weight but no change in smoking status. The authors concluded that, overall, the (multi-factorial) intervention was effective.

These benefits have to be viewed against the background of the magnitude of the intervention employed in these studies. This included seven study-related educational meetings for the physicians involved, of which four were devoted to education on risk factor management and three to logistic issues relating to the studies. During the 6 months of the study, the subjects were seen at monthly intervals (primarily for renewing prescriptions). The physicians used these sessions to reinforce the aims of the study and the need to make lifestyle changes such as smoking cessation. The subjects also met with dietitians who provided additional information relating to the modified Mediterranean diet that the subjects were prescribed. The drop-out rate in the various categories of CKD was said to be similar though no data was provided. The latter is an important item of information when one attempts to evaluate the cost-effectiveness of the intervention, simply because this degree of patient contact is rarely seen in practice outside the context of a clinical trial. It is clear that intensive lifestyle interventions have considerable potential for successful modification of cardiovascular risk factors, and prior reports have demonstrated these benefits in impeding development of the metabolic syndrome [2] and in achieving weight loss in patients with obesity [3]. However, as in the investigation of Athyros et al. [1], the latter two trials entailed a very high frequency of patient visits that included intensive education and counseling provided by teams of health professionals, Thus, all three of these studies provide proof of concept but current systems of medical practice present formidable obstacles that preclude application of these methods to current clinical care.

Another issue which is likely to have an impact on whether these findings are generalizable beyond Greece (or the European Community) is whether the medications were provided at no cost to subjects. A recent study by Choudhry et al. [4] has shown that elimination of copayments for drugs (in the U.S.) after myocardial infarction increased rates of medication adherence by only $4-6 \%$ in those for whom the drugs were free and the overall rate of adherence remained at approximately $50 \%$. Furthermore, there was no significant reduction in the primary outcome of a first major vascular event or revascularization.
The flip side of this coin is how physicians behave when presented with evidence from a clinical trial. Borden et al. [5] examined the impact on physician practices, of results of the COURAGE trial which compared the efficacy of optimal medical therapy and percutaneous coronary intervention $(\mathrm{PCl})$ in patients with stable angina [6]. Despite clear evidence that optimal medical management was equally as effective as $\mathrm{PCl}$, there was no perceptible change in the prescribing practices of physicians toward achieving optimal medical therapy [5]. These trends are confirmed in another recent study which sought to examine the efficacy of an Internet-delivered intervention to physician providers to improve cardiovascular management of post-MI patients. The study was undertaken in Veterans Hospitals in the U.S. over a period of 27 months. It was found that the Internet-delivered system improved only 1 out of 7 indicators of cardiovascular care in ambulatory post-MI patients [7].

Thus, availability of a guideline, evidence from controlled clinical trials and free medications notwithstanding, there is clearly a need for an alternative algorithm for the provision of optimal management of cardiovascular risk factors.

\section{References}

1. Athyros V, Hatzitolios A, Karagiannis A, et al. Improving the implementation of current guidelines for the management of major coronary heart disease risk factors by multifactorial intervention. The IMPERATIVE analysis. Arch Med Sci 2011; 7: 984-92.

2. Orchard T, Temprosa M, Goldberg R, et al.; Group DPPR. The effect of metformin and intensive lifestyle intervention on the metabolic syndrome: the Diabetes Prevention Program randomized trial. Ann Intern Med 2005; 142: 611-9.

3. Waddeb T, Volger S, Sarwer D, et al. A two-year randomized trial of obesity treatment in primary care practice. N Engl J Med 2011; 365: 1969-79.

4. Choudhry NK, Avorn J, Glynn RJ, et al. Full coverage for preventive medications after myocardial infarction. N Engl J Med, e-publ.

5. Borden WB, Redberg RF, Mushlin Al, Dai D, Kaltenbach LA, Spertus JA. Patterns and intensity of medical therapy in patients undergoing percutaneous coronary intervention. JAMA 2011; 305: 1882-9.

6. Boden WE, O'Rourke RA, Teo KK, et al. Optimal medical therapy with or without $\mathrm{PCl}$ for stable coronary disease. N Engl J Med 2007; 356: 1503-16.

7. Levine D, Funkhouser E, Houston T, et al. Improving care after myocardial infarction using a 2-year internet-delivered intervention: the department of veterans affairs myocardial infarction-plus cluster-randomized trial. Arch Intern Med 2011; 171: 1910-7. 